\title{
Dirty rag costs Arianespace forty million dollars
}

\section{Parls}

A DISCARDED rag caused the explosion which wrecked flight 36 of Europe's Ariane-4 commercial launcher in February (see Nature 344, 7; 1 March 1990). Tests on fragments of flexible tubing salvaged from the wreck are still being carried out by experts at the Saclay Jet Propulsion Test Centre near Paris, but the discovery that a main water valve in the cooling circuitry had become blocked by "textile material" confirms one of four principal conclusions of a 180-page report made public last week.

The report follows investigations by a seven-person specialist board of enquiry set up by the European Space Agency (ESA) and Arianespace, the Paris-based launch consortium, immediately after the incident. According to Arianespace chairman, Frédéric d'Allest, Ariane launches should now be able to resume this summer.

On the basis of initial telemetry data, the loss of the mission was attributed to a decrease in thrust in engine $\mathrm{D}$, one of the four first-stage Viking motors. This drop occurred 6.2 seconds after ignition and, d'Allest told the press last week, was the result of "an almost total obstruction of the water feeding circuit of Viking motor D". The obstruction occurred upstream of the motor, before the water pump, and the motor itself is not under suspicion.

The board last week felt the probable cause of the obstruction was either the "untimely presence of a foreign object in the water pipes or a failure in the main water valve". The water pipes are part of the cooling system of the turbopumps in the Ariane first stage. But the latest tests at Saclay have now shown that the valve itself was not to blame.

The discovery of the rag follows a remarkable and hazardous recovery operation. Working for almost 1,600 hours in total darkness in mangrove swamps and deep water, teams of divers recovered over 450 pieces of the disintegrated rocket. The divers were aided by legionnaires, Paris fire brigade officers from the launch centre and scientists of the Grenoble Research Centre (LETI) equipped with highly sensitive detection apparatus. On 9 April most of the water tank and 4 to 5 metres of water feeding pipe were recovered and were sent to France the next day for analyses.

The question now taxing Arianespace is how the rag went unnoticed. A company press communique says "the most likely cause for the presence of this textile material is tied to unusual servicing on this tubing". On Monday, an Arianespace spokesman said that the tube had initially been installed on another rocket, but was not needed. It was taken off and stored until finally being reinstalled on flight 36 . It was this "exceptional" procedure, he said, which had allowed the rag to go unnoticed.

This points to a weakness in safety checks following very unusual procedures, he said.

The investigation has so far also revealed that there was an "incipient fire" in the propulsion bay of one of the liquid strap-on boosters (PAL 3) 2.4 seconds after firing of the motors.

This was caused by leaking nitrogen peroxide propellant but, says the board of inquiry, the two incidents do not seem to have been related.

The board, chaired by Jacques Durand, head of the Arianespace programme at ESA, has put forward 44 recommendations, nine of which, they say, must be acted upon before flight 37 receives authorization.

The recommendations mainly concern tightening up verification procedures during launch integration and additional checks on liquid coolant circuits. Extra thermal blanketing is likely to be used on sensitive circuits exposed to a fire risk, so that a small fire would not jeopardize the entire mission.

The loss of flight 36 has so far cost Arianespace between FF200 and FF300 million ( $\$ 36$ to $\$ 54$ million), but d'Allest says that clients still have confidence in Ariane's reliability. Four new launch contracts have been signed since the crash: with the US company Hughes Communications, the Berlin Institute of Technology and France Telecom. D'Allest thinks launches should resume in the summer and that four launches could still be carried out this year.

Priority in the future will be given to the Japanese customers, the Japan Broadcasting Company (NHK) and Space Communication Corporation (SCC) who lost their telecommunications satellites in the crash. Both satellites were built by US manufacturers. SSC's Superbird-B satellite was made by Ford Aerospace for television and defence use.

The other satellite, BS-2X was built by General Motors at a cost of $\$ 93$ million, to boost NHK's satellite television broadcasting capability. Now the company still has only one satellite in operation, Yuri $2 \mathrm{~B}$, which is expected to stop functioning in about a year. The future of the satellite service now depends on the successful launch of the follow-up to Yuri-2B, BS-3, by Japan's National Space Development Agency, in August.

\section{$\mathrm{CB}$ goes critical}

GOVERNMENT support for British industrial research and development needs overhauling, according to a report* published last week by the Confederation of British Industry (CBI). Through the Department of Trade and Industry (DTI)'s Enterprise Initiative, about $£ 100$ million of public money is spent annually on industrial research and technology transfer, in fields from aerospace to biotechnology.

The CBI report argues that the process of applying for DTI research grants needs to be streamlined, since "some companies claim that additional management costs incurred as a result of grant application now equal . . . the grant itself'.

Small companies also need more advice on how to implement existing technology, the CBI says. The report suggests that a separate "technology consultancy" could be set up within the DTI to promote technology transfer.

P.A.

*Technology and Enterprise - a CBI review of DTI support for technology in UK industry.

\section{RESEARCH SUPPORT}

\section{Japan catching up}

FIGURES from the US National Science Foundation (NSF)'s National Science Board biennial report Science and Engineering Indicators - 1989 show that the United States still spends more on research and development than the combined efforts of the next four nations Japan, West Germany, France and the United Kingdom. Over the past decade,

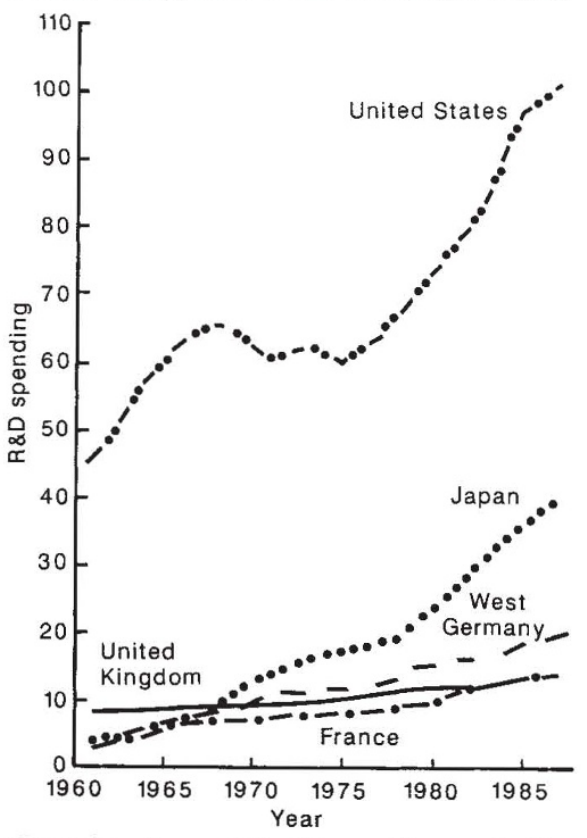

there has been virtually no change in the US position of dominance - now 54 per cent of the total expenditure of the five nations. But the huge gap between the United States and its principal high-technology competitor, Japan, narrows greatly when only non-military research is considered. 